\title{
Haemadsorption and Haemagglutination by Mycoplasmas
}

\author{
BY R. J. MANCHEE AND D. TAYLOR-ROBINSON \\ M.R.C. Clinical Research Centre, Harvard Hospital, Salisbury, Wiltshire
}

(Accepted for publication 25 August 1967)

\begin{abstract}
SUMMARY
Factors concerned in demonstrating haemadsorption and haemagglutination and their occurrence among different mycoplasmas were investigated. Haemadsorption occurred best to colonies which had recently developed on agar at $\mathrm{pH}$ 6.5. Mycoplasmas isolated from various bird and animal sources, e.g. Mycoplasma gallisepticum, $M$. agalactiae, $M$. bovigenitalium and $M$. pulmonis, haemadsorbed with erythrocytes from a wide range of species. However, not all strains within a serotype haemadsorbed. Thus, the 'Negroni' strain of $M$. pulmonis did not. Haemadsorption could be inhibited by crowding of colonies on agar and by the addition of specific antiserum to the colonies. Generally, antiserum titres obtained by haemadsorption inhibition were low in comparison with those obtained by metabolic inhibition, and haemadsorption inhibition was not useful as a routine serological technique.

The development of the haemagglutinin of Mycoplasma gallisepticum in liquid medium was studied in detail; a change in the $\mathrm{pH}$ value of the medium could be used as an index of its development and it was intimately associated with the organism. The centrifuged deposits of other mycoplasmas, from birds, cattle, goats, man, rodents and pigs, and which were grown in liquid medium also haemagglutinated, but generally to low titre. Haemagglutination

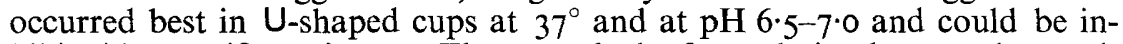
hibited by specific antiserum. There was lack of correlation between haemadsorption and haemagglutination; both these phenomena were exhibited by some mycoplasmas, others haemadsorbed only, and still others haemagglutinated only.
\end{abstract}

\section{INTRODUCTION}

Del Giudice \& Pavia (1964) reported that erythrocytes from several animals adsorbed to Mycoplasma pneumoniae colonies on solid medium. The phenomenon did not occur with other prototype human oral mycoplasmas, or with miscellaneous mycoplasma strains. Haemadsorption was inhibited by sera from patients convalescing from primary atypical pneumonia and from whom $M$. pneumoniae had been isolated, and it was suggested that the method could be useful for sero-diagnosis and identification of $M$. pneumoniae. Several years earlier van Herick \& Eaton (1945) had shown that a mycoplasma isolated from eggs haemagglutinated, and other workers found haemagglutination to occur widely among mycoplasmas from birds (Roberts, I964; Dierks, Newman \& Pomeroy, 1967). It may be inhibited by antibody (Jungherr, Luginbuhl \& Jacobs, I953) and the haemagglutination-inhibition technique has been used extensively, in particular with $M$. gallisepticum.

We suspected that the phenomena of haemagglutination and haemadsorption might be related. Since Mycoplasma gallisepticum readily agglutinated erythrocytes it seemed possible that its colonies, and perhaps those of other mycoplasmas, might 
haemadsorb. Furthermore, it seemed unreasonable that haemagglutination should occur solely with mycoplasmas from birds. Therefore, mycoplasmas from various sources have been examined for colony haemadsorption and for their haemagglutinating ability, and the conditions under which the phenomena are best demonstrated have been investigated. The occurrence of haemadsorption and haemagglutination by mycoplasmas isolated from several animal and avian hosts is discussed in relation to their pathogenicity.

\section{METHODS}

Medium. The medium used for culture of the organisms was basically that described by Chanock, Hayflick \& Barile (1962) and by Hayflick (1965). Liquid medium consisted of Difco PPLO broth ( $70 \mathrm{ml}$.), $25 \%$ (w/v) aqueous extract of DCL dried yeast (Io ml.) and unheated Burroughs Wellcome horse serum no. $6(20 \mathrm{ml}$.). Thallium acetate (I/2000) and penicillin G (I000 units/ml.) were used as bacterial inhibitors. In addition, in order to detect growth of glucose-fermenting mycoplasmas, $0.1 \%$ glucose and $0.002 \%$ phenol red were added and the medium adjusted to $\mathrm{pH} 7.8$; for mycoplasmas splitting arginine, $0.1 \%$ of this substrate and $0.002 \%$ phenol red were added and the medium adjusted to $\mathrm{pH} 7 \cdot 0$. Solid medium was prepared by adding $\mathrm{I} g$. Oxoid Ionagar no. 2 to $100 \mathrm{ml}$. of liquid medium, since we found that various batches of Difco PPLO agar were inhibitory to mycoplasma growth.

Mycoplasmas. The mycoplasmas tested, the animal or bird species from which they were isolated, and those persons from whom strains were obtained are shown in Table I.

Propagation. Mycoplasma colonies for haemadsorption tests were obtained in the following manner. A stock culture of the organism (stored at $-70^{\circ}$ ) was diluted in liquid medium in serial tenfold steps, and $0.1 \mathrm{ml}$. amounts were spread on $5 \mathrm{ml}$. of solid medium in $5 \mathrm{~cm}$. diameter plastic Petri dishes; excess moisture from the agar surface was removed by incubation for $\mathrm{I} \mathrm{hr}$ at $37^{\circ}$ before inoculation. Subsequently, the dishes were incubated at $37^{\circ}$ in a humid atmosphere, which usually consisted of a mixture of $95 \%(\mathrm{v} / \mathrm{v}) \mathrm{N}_{2}$ and $5 \%(\mathrm{v} / \mathrm{v}) \mathrm{CO}_{2}$, for periods of from 2 to 4 days depending on the growth rate of the organism.

For haemagglutination tests mycoplasmas were grown in $50 \mathrm{ml}$. amounts of liquid medium contained in a $4 \mathrm{oz}$. flat medicine bottle. The cultures were incubated at $37^{\circ}$ until the $\mathrm{pH}$ value of the medium had changed by at least $\mathrm{I} \mathrm{pH}$ unit. The organisms were then centrifuged for $15 \mathrm{~min}$. at $3750 \mathrm{~g}$. The supernatant fluid was discarded, and the pellet washed 3 times in Io $\mathrm{ml}$. of $\mathrm{pH} 7 \cdot 2$ phosphate-buffered saline (PBS), resuspended in $\mathrm{I} \mathrm{ml}$. of PBS, and stored at $-20^{\circ}$. PBS consisted of: $8.5 \mathrm{~g}$. NaCl, $0.98 \mathrm{~g}$. $\mathrm{Na}_{2} \mathrm{HPO}_{4}, 0.74$ g. $\mathrm{NaH}_{2} \mathrm{PO}_{4} \cdot 2 \mathrm{H}_{2} \mathrm{O}$ in 11 . water.

Erythrocytes. Erythrocytes were obtained from cattle, guinea pigs, fowl, man, monkeys, mice, rabbits, rats and turkeys. The blood was mixed with a citric acidsodium citrate-glucose anticoagulant (ACD) immediately after collection. It was then centrifuged at $550 \mathrm{~g}$ for Io min., and the pellet resuspended in to times its volume of glucose + gelatin + veronal solution (DGV; Clarke \& Casals, I958) and recentrifuged. This process was repeated twice more, the pellet being suspended finally to produce a $10 \%$ suspension of erythrocytes in DGV, which was stored at $4^{\circ}$ until required.

Haemadsorption (h.ad.) and haemadsorption-inhibition (h.ad.i.). The stock 10\% 
Table I. Mycoplasmas investigated

Mycoplasma

M. anatis

M. gallinarum (strain PG 16 )

M. gallinarum (I I other strains)

M. gallisepticum (strain A 514)

M. gallisepticum (strains s6, A 5969)

$M$. gallisepticum (5 other strains)

$M$. iners

$M$. meleagridis

M. synoviae

IOWA 695

WR I, WR/W I 20, WR/W 128

I 86

658

M. bovigenitalium (strains PG I I, PG I2, PG 48)

$M$. bovigenitalium (strain $\mathbf{1 8 3 6}$ )

$M$. bovigenitalium (strain DAVIDSON 37)

$M$. mycoides (strain GLADYSDALE)

$M$. mycoides (strain T3)

DONETTA, D I 2, N 29, 5M 331

$M$. canis (strain PG 14)

M. maculosum (strain PG I5)

$M$. spumans (strain PG I3)

$M$. agalactiae (strain PG 2)

M. agalactiae

$M$. mycoides var. capri

$M$. hominis (2 strains)

$M$. hominis (strains PG 21, DC63, V2785)

$M$. fermentans (strain $\mathrm{PG} \mathrm{I} 8$ )

$M$. orale I (strain CH 19299)

$M$. orale I (3 other strains)

$M$. orale II (strain $\mathrm{CH} 20247$ )

$M$. pneumoniae (strain $\mathrm{FH}$ )

$M$. pneumoniae (6 other strains)

M. salivarium (strain PG 20)

$M$. salivarium (3 other strains)

$M$. arthritidis (strain PG 6)

$M$. hominis II (strain PG 27)

$M$. histotropicus (strain SABIN C)

$M$. neurolyticum (strain SABIN A)

$M$. neurolyticum (strain PG 28)

$M$. pulmonis (strain PG 22)

M. pulmonis (strain PG 34)

$M$. pulmonis (strain KON)

M. pulmonis (strain $\mathrm{M} \mathrm{I}$ )

$M$. pulmonis (strain 880)

M. pulmonis (Negroni agent strain)

$M$. pulmonis (6 other Negroni strains)

PG 5

M. granularum

$M$. hyorhinis (strains F, S7, SEPG, SEPSK, SEP 200)

$M$. hyorhinis (strain GDL)

B I, B 2, B3, B 4, B 5, в 6

$M$. laidlawii (strains A, B)

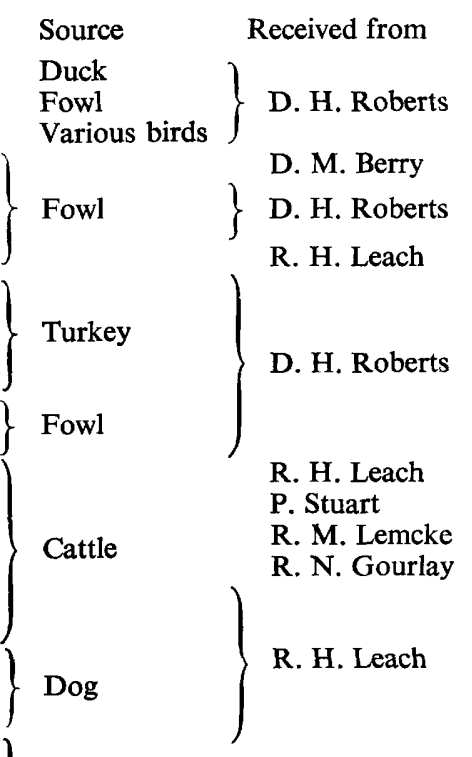

Goat

R. M. Lemcke

R. H. Leach

S. Stewart

R. M. Chanock

S. Stewart

Man

R. M. Chanock

B. E. Andrews

R. M. Chanock

S. Stewart

$\begin{array}{ll}\text { Rat } & \text { J. G. Tully } \\ \text { Man* } & \text { R. M. Chanock }\end{array}$

Man*

\} J. G. Tully

Mouse

R. H. Leach

\} Rat

Mouse

\} R. M. Lemcke

R. H. Leach

Tissue culture $\uparrow$

R. M. Chanock

B. E. Andrews

Rat J. G. Tully

\} Pig $\}$

Z. Dinter

Tissue culture

Pig

R. M. Chanock

Sewage

Z. Dinter

R. H. Leach

* Isolated from man but now considered to be a strain of $M$. arthritidis (Edward \& Freundt, 1965),

† Isolated from tissue cultures inoculated with human leukaemic material. Subsequently identified as strain of $M$. pulmonis (Fallon et al. 1965; Leach \& Butler, 1966).

\$ Isolated from uninoculated HEp-2 cells (Butler \& Leach, 1964) and identified as M. hyorhinis (Purcell et al. I966a). 
suspension of erythrocytes was diluted, either in PBS or in Difco PPLO broth, to produce a $0.5 \%$ suspension of which about $2 \mathrm{ml}$. was poured on to the agar surface. The cultures were then incubated, usually at $37^{\circ}$, for $15-30 \mathrm{~min}$. Then, by means of a 'plate' microscope, giving a magnification of $\times 50$ to $\times 150$, colonies were observed with the erythrocyte suspension in situ, and again after the suspension had been removed and the agar surface washed with 5-10 ml. of PBS or PPLO broth.

For h.ad.i., a microtechnique was developed in order to conserve antisera. Mycoplasmas were inoculated on to the surface of $0 . \mathrm{I} \mathrm{ml}$. amounts of agar medium contained in the cups of Linbro plastic disposo-trays (S-MRC-96; Linbro Chemical Co. Inc., New Haven, Connecticut, U.S.A.). The stock mycoplasma suspensions were diluted to produce about five to twenty colonies per cup after incubation at $37^{\circ}$ in a humid atmosphere of $95 \%(\mathrm{v} / \mathrm{v}) \mathrm{N}_{2}$ and $5 \%(\mathrm{v} / \mathrm{v}) \mathrm{CO}_{2}$. Twofold antiserum dilutions $(0.025 \mathrm{ml}$.) in PBS were made with Takátsy spiral loops and the $0.025 \mathrm{ml}$. amounts transferred to the agar. After incubation of the disposo-tray at room temperature for $30 \mathrm{~min}$., $0.025 \mathrm{ml}$. of a $0.5 \%$ erythrocyte suspension was added to each cup and the tray incubated at $37^{\circ}$ for $15-30 \mathrm{~min}$. Excess erythrocyte suspension was then removed by dipping and agitating the tray in PBS. The colonies were then observed microscopically for haemadsorption.

In some instances, colonies which had developed on agar medium contained in Petri dishes were used. Blocks of agar about $\mathrm{I} \mathrm{cm}$. square and bearing the colonies were cut out and transferred to empty Petri dishes. The subsequent procedures were as described previously.

Haemagglutination (h.a.) and haemagglutination-inhibition (h.i.). Serial twofold dilutions of the mycoplasma suspension were made in PBS or PPLO broth diluent by using Takátsy loops and Linbro disposo-trays. Then $0.025 \mathrm{ml}$. of a $0.5 \%$ erythrocyte suspension and the same volume of diluent were added to give a total volume of $0.075 \mathrm{ml}$. in each cup. The trays were covered with 'Scotch' brand clear adhesive tape, shaken, and incubated, usually at $37^{\circ}$, for about I hr. Haemagglutination was graded as follows: $++++=100 \%$ agglutination, $+++=75 \%,++=50 \%$, $+=25 \%$. One h.a. unit was contained in the highest dilution of mycoplasma suspension at which approximately $75 \%$ or more of the erythrocytes were agglutinated.

For the h.i. test, serial twofold dilutions of antiserum in $0.025 \mathrm{ml}$. volumes were made in a disposo-tray, and $4 \mathrm{~h} . \mathrm{a}$. units of antigen in $0.025 \mathrm{ml}$. were added to each cup. The mixtures were incubated at room temperature for $30 \mathrm{~min}$., and then $0.025 \mathrm{ml}$. of $0.5 \%$ erythrocyte suspension was added to each cup, and the tray incubated at $37^{\circ}$ for about $\mathrm{r}$ hr. The antiserum titre was the highest dilution at which at least $75 \%$ of the erythrocytes were not agglutinated.

Metabolic inhibition (m.i.). These tests were performed as described in detail previously (Taylor-Robinson, Purcell, Wong \& Chanock, 1966; Purcell, TaylorRobinson, Wong \& Chanock, 1966b).

\section{RESULTS}

\section{Haemadsorption}

The basic technique used to detect haemadsorption is described in the Methods section. However, various factors which might influence the demonstration of haemadsorption were investigated. 
Agar medium. The constituents were not varied, but media at $\mathrm{pH} \mathrm{8.0,7.0} \mathrm{and} 6.5$ were used. Agar medium did not gel adequately at $\mathrm{pH} 6 \cdot 0$, and therefore was not used. The number of colonies which developed on agar medium at each $\mathrm{pH}$ value was

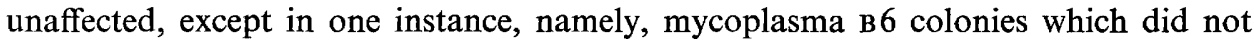
develop surface peripheral growth at $\mathrm{pH} \mathrm{8.0.} \mathrm{Since} \mathrm{erythrocytes} \mathrm{adhered} \mathrm{to} \mathrm{the}$ periphery and not to the central 'nipple' portion of the colonies of this mycoplasma, it was necessary to use agar at a low $\mathrm{pH}$ value in order to demonstrate haemadsorption. Also, growth of other mycoplasmas on agar at $\mathrm{pH} 6.5$ produced colonies, the surface growth of which did not detach easily from the agar when an erythrocyte suspension was added. For these reasons agar at $\mathrm{pH} 6.5$ was used in subsequent experiments.

Culture atmosphere. The effect of the atmosphere in which the culture was grown on subsequent haemadsorption was investigated with Mycoplasma pneumoniae and $M$. agalactiae. Colonies of these mycoplasmas developed just as well in an atmosphere containing a mixture (v/v) of $95 \%$ air $+5 \% \mathrm{CO}_{2}$ as in a mixture of $95 \% \mathrm{~N}_{2}+5 \% \mathrm{CO}_{2}$. The rate and extent of haemadsorption to colonies which had developed under either condition was the same. Since colonies of most mycoplasmas develop best, or in some instances, only in an atmosphere (v/v) of $95 \% \mathrm{~N}_{2}+5 \% \mathrm{CO}_{2}$, this was used for subsequent cultures.

Age of colonies. Agar cultures of several mycoplasmas were incubated for 4 days at $37^{\circ}$ and duplicate cultures were incubated for Io days, and at each of these times the colonies were tested for haemadsorption. Colonies of mycoplasmas which haemadsorbed strongly after 4 days, haemadsorbed weakly after Io days, i.e. fewer erythrocytes attached. Colonies of Mycoplasma agalactiae which haemadsorbed strongly at 4 days did not do so at all after Io days, due to the development of a crystalline film which covered the colonies and agar at this time. Colonies of mycoplasma $\mathrm{B} 6$ which haemadsorbed weakly at 4 days did not do so at all at Io days. Subsequently, for routine use, haemadsorption tests were performed with colonies which had recently developed or had been incubated only until there was no obvious increase in colony size. This usually took 3 or 4 days.

Crowding of colonies. The number of colonies on agar medium was an extremely important factor in the demonstration of haemadsorption. In preliminary experiments with several mycoplasma strains, in particular Mycoplasma agalactiae, $M$. gallisepticum and $M$. pneumoniae, it was noticed that discrete colonies at the edge of a crowded area of colonies haemadsorbed, but those in the crowded area did not. Therefore, serial tenfold dilutions of the organisms were inoculated on agar medium so that, after incubation, the number of colonies in each agar dish ranged from confluency to a few only. After the addition of erythrocytes, isolated colonies haemadsorbed but colonies which were crowded did not. This is illustrated in Fig. I and in Pl. I, figs. I, 2. Because of this phenomenon, care was taken in other experiments to use agar cultures with not more than about Ioo colonies.

Species of erythrocytes. Del Giudice \& Pavia (I964) reported that erythrocytes from several animal species adsorbed to Mycoplasma pneumoniae colonies. This was confirmed in the present experiments since erythrocytes of all the species tested adsorbed to colonies of this mycoplasma (Table 2). However, because of the difficulty of testing such a wide variety of erythrocytes against all the mycoplasmas, only a few species of erythrocytes were tested. The following were used: the 'homologous' species of 
erythrocytes, i.e. erythrocytes from the bird or animal species from which the mycoplasma was originally isolated, and one or more heterologous species, in particular, guinea-pig erythrocytes. In most instances, a colony which adsorbed the homologous erythrocytes adsorbed the heterologous erythrocytes also. Exceptions to this were observed with $M$. bovigenitalium strain 1836 , which adsorbed guinea-pig, but not bovine erythrocytes, and the porcine mycoplasma B I which adsorbed pig, but not guinea-pig erythrocytes.

Suspending fluid and age of erythrocytes. Washed guinea-pig erythrocytes stored at $4^{\circ}$ in DGV were resuspended in PBS ( $\mathrm{pH} 7 \cdot 2$ ) or in Difco PPLO broth at $\mathrm{pH} \mathrm{6.5,7.0}$ and $8 \cdot 0$. The adsorption of erythrocytes, suspended in these various fluids, to colonies of Mycoplasma pneumoniae, $M$. gallisepticum, mycoplasma B6 and $M$. laidlawii A was tested at $37^{\circ}$. Erythrocytes did not adsorb to colonies of $M$. laidlawii A under any conditions and no difference in the rate or extent of haemadsorption to colonies of the other mycoplasmas was noted with erythrocytes in the various suspensions. Therefore, further experiments were made with $\mathrm{pH} 7 \cdot 2$ PBS as the erythrocyte suspending fluid. In addition, erythrocytes stored at $4^{\circ}$ in DGV for various periods up to I month adsorbed as readily as fresh erythrocytes.

Table 2. Effect of temperature on haemadsorption by three mycoplasmas

\begin{tabular}{|c|c|c|c|c|}
\hline \multicolumn{2}{|c|}{ Incubation } & \multirow[b]{2}{*}{ M. gallisepticum } & \multirow{2}{*}{$\begin{array}{l}\text { Mycoplasma } \\
\text { DONETTA }\end{array}$} & \multirow{2}{*}{$\underset{\mathbf{A}}{M . ~ l a i d l a w i l}$} \\
\hline Time & Temperature & & & \\
\hline $15 \mathrm{~min}$. & $\begin{array}{r}37^{\circ} \\
22^{\circ} \\
4^{\circ}\end{array}$ & $\begin{array}{c}+++^{*} \\
++ \\
++\end{array}$ & $\begin{array}{c}++ \\
+ \\
-\end{array}$ & $\begin{array}{l}- \\
- \\
-\end{array}$ \\
\hline I $80 \mathrm{~min}$. & $\begin{array}{r}37^{\circ} \\
22^{\circ} \\
4^{\circ}\end{array}$ & $\begin{array}{l}+++ \\
++++ \\
++++\end{array}$ & $\begin{array}{c}++ \\
++ \\
-\end{array}$ & $\begin{array}{l}- \\
- \\
-\end{array}$ \\
\hline
\end{tabular}

Table 3. Mycoplasmas which haemadsorb with homologous and guinea-pig erythrocytes
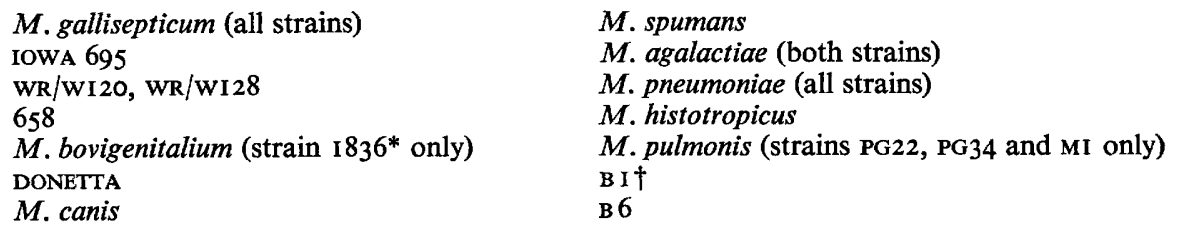

Other mycoplasmas shown in Table I did not haemadsorb.

* Adsorbed guinea-pig but not bovine erythrocytes.

$\dagger$ Adsorbed pig but not guinea-pig erythrocytes.

Temperature of reaction. The effect of temperature on haemadsorption to colonies of three distinct mycoplasmas was investigated. The results are shown in Table 2. Adsorption to colonies of Mycoplasma gallisepticum was most rapid at $37^{\circ}$ but occurred at $4^{\circ}$ also. Similarly, adsorption to colonies of mycoplasma DONETTA was most rapid at $37^{\circ}$, but was not observed at $4^{\circ}$. Adsorption to colonies of $M$. laidlawii A 
was not observed at any temperature after prolonged incubation. Incubation at $37^{\circ}$ was used for subsequent tests.

Haemadsorption among different mycoplasmas. A number of mycoplasma strains belonging to 39 serotypes (Table I) were then examined for colony haemadsorption using the conditions outlined above. Fourteen of the serotypes were observed to haemadsorb, as shown in Table 3. Colonies of all the strains of Mycoplasma gallisepticum and $M$. pneumoniae that were tested haemadsorbed. It is noteworthy, however, that not all strains of other serotypes did likewise. Thus only one of five strains of $M$. bovigenitalium did so.

\section{Haemadsorption inhibition}

The inhibition of erythrocyte adsorption to colonies of Mycoplasma pneumoniae by antiserum was reported by Del Giudice \& Pavia (1964). In the present investigation, inhibition was investigated with rabbit antisera to three of the haemadsorbing mycoplasmas, including $M$. pneumoniae. In a preliminary test with $M$. pneumoniae antiserum, inhibition was not demonstrated in the absence of unheated guinea-pig serum. The subsequent h.ad.i. tests were performed, therefore, with guinea-pig serum. The results, together with those of metabolic inhibition tests performed on the same antisera, are shown in Table 4. The homologous h.ad.i. antiserum titre for each mycoplasma was low in comparison with the metabolic inhibition titre. Because of these low titres, cross h.ad.i. tests to determine specificity were not performed.

Table 4. Haemadsorption inhibition with hyper-immune rabbit sera

\begin{tabular}{|c|c|c|}
\hline \multirow[b]{2}{*}{ Mycoplasma } & \multicolumn{2}{|c|}{$\begin{array}{l}\text { Homologous antiserum titre } \\
\text { (reciprocal) measured by }\end{array}$} \\
\hline & $\begin{array}{l}\text { Haemadsorption } \\
\text { inhibition }\end{array}$ & $\begin{array}{l}\text { Metabolic } \\
\text { inhibition }\end{array}$ \\
\hline M. gallisepticum (s6) & 40 & 640 \\
\hline M. agalactiae & 20 & 10,240 or $>$ \\
\hline M. pneumoniae (FH) & 40 & 320 \\
\hline
\end{tabular}

\section{Haemagglutination}

Several factors which could affect haemagglutination were investigated.

Growth of mycoplasma. Since it was impractical to study in detail the growth and development of haemagglutinin for each mycoplasma, a detailed examination of a known haemagglutinating mycoplasma, namely Mycoplasma gallisepticum, was performed. This organism was grown in liquid medium and samples were removed at $24 \mathrm{hr}$ intervals and examined for $\mathrm{pH}$ value, number of viable organisms (colony forming units), and haemagglutinin with chicken erythrocytes. In addition, each sample was centrifuged at $3750 \mathrm{~g}$ for $15 \mathrm{~min}$. and the haemagglutinin titre of the supernatant fluid and the deposit was determined. The results are shown in Fig. 2. The maximum number of viable organisms occurred after 3 days of incubation, when the $\mathrm{pH}$ value of the medium had fallen from $7 \cdot 6$ to $7 \cdot 0$. However, the maximum haemagglutinin titre of the deposit was not attained until after 5 days of incubation, when the $\mathrm{pH}$ value had fallen to 6.2. Haemagglutinin was not detected in the supernatant fluid after centrifugation of any of the samples, indicating its association with the whole organism. 
No. of colonies

on agar plate

$10^{2}$

$10^{3}$

$10^{4}$

$10^{5}$

$10^{6}$
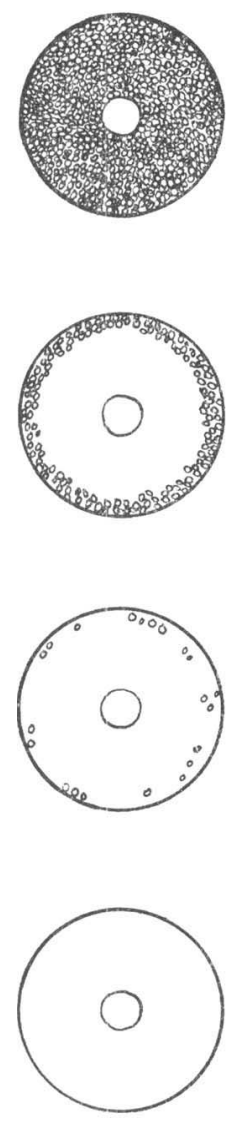

Fig. I
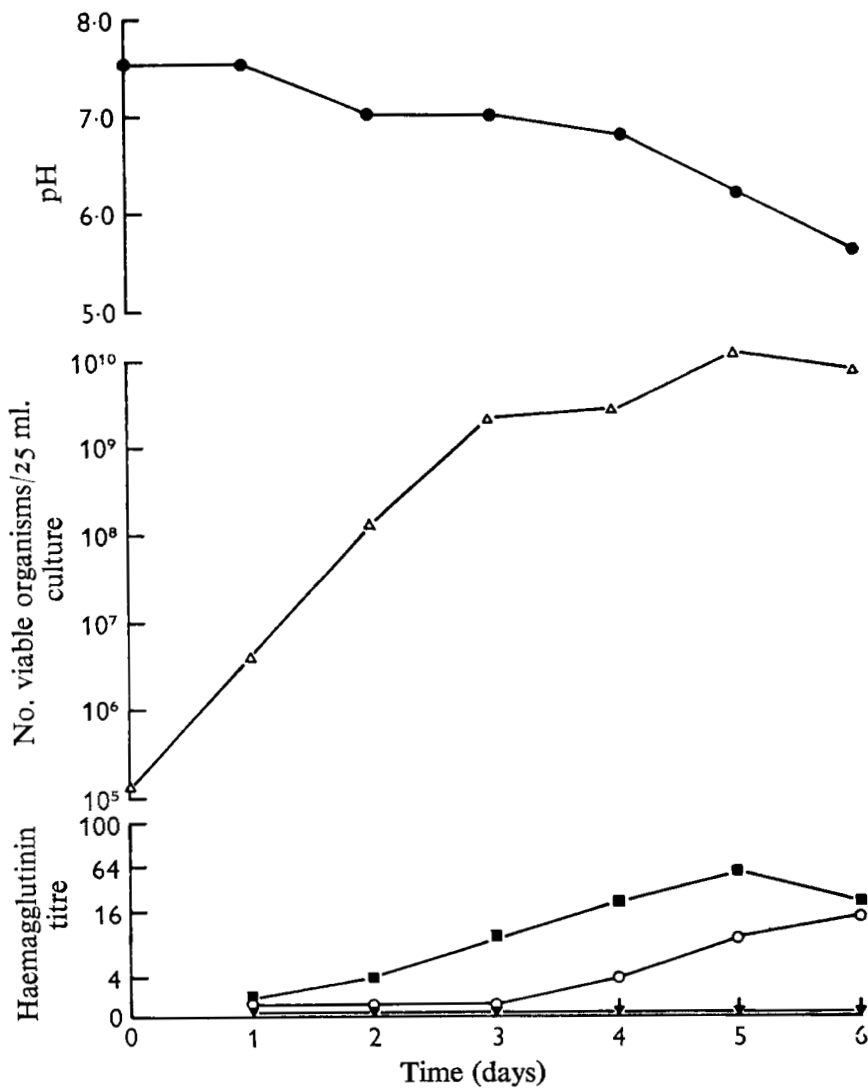

Fig. 2

Fig. I. Inhibitory effect of increasing numbers of colonies on the adsorption of guinea-pig erythrocytes to Mycoplasma pneumoniae colonies. $\times 150$.

Fig. 2. Development of haemagglutinin and viable organisms in a liquid culture of $M y c o-$ plasma gallisepticum (strain A 5969). $-\mathrm{pH} ; \triangle$, number viable organisms $/ 25 \mathrm{ml}$. culture; $\square$, haemagglutinin titre of centrifuged deposit from $25 \mathrm{ml}$. culture; $O$, haemagglutinin titre of culture before centrifugation; $\downarrow$, haemagglutinin titre of supernatant fluid after centrifugation. 
As a result of the above experiment, cultures of other mycoplasmas were incubated until the $\mathrm{pH}$ value had changed by at least I unit or until there was no further change in $\mathrm{pH}$ value as judged by a change in colour of the indicator. The cultures were then centrifuged as before and the deposits tested for haemagglutinin.

Diluent and $p H$ value. Preliminary haemagglutination tests with several mycoplasmas, colonies of which had been observed to haemadsorb, were made with Difco PPLO broth adjusted with $\mathrm{HCl}$ to $\mathrm{pH} 5 \cdot 5,6 \cdot 0,6 \cdot 5,7 \cdot 0,7 \cdot 5$, and PBS (pH 7.2). Haemagglutination titres were higher at $\mathrm{pH} 6.5-7.0$ than above; at $\mathrm{pH} 5.5$ lysis of erytbrocytes occurred. Haemagglutination titres and patterns were the same when broth at $\mathrm{pH} 7 \cdot 0$ and PBS ( $\mathrm{pH} 7 \cdot 2)$ were used. Most subsequent tests were performed with PBS as diluent.

Temperature of reaction and type of cup. Several tests were made at $37^{\circ}, 22^{\circ}$ and $4^{\circ}$ in U-shaped and V-shaped cups. Haemagglutination titres were optimal at $37^{\circ}$ and the patterns were most distinct and easily readable in $\mathrm{U}$-shaped cups.

With the conditions as outlined above, namely PBS diluent at $\mathrm{pH} 7 \cdot 2$, U-shaped cups and incubation at $37^{\circ}$, deposits of all the available mycoplasmas were examined in haemagglutination tests with erythrocytes from several species. The results are presented in Table 5. In general, h.a. titres were of a low order and a mycoplasma which agglutinated erythrocytes did not necessarily do so with erythrocytes of all the species tested.

Table 5. Mycoplasmas which haemagglutinate

\begin{tabular}{|c|c|c|c|c|}
\hline \multirow[b]{2}{*}{ Mycoplasma } & \multicolumn{4}{|c|}{$\begin{array}{l}\text { Reciprocal haemagglutination titre* with } \\
\text { erythrocytes from }\end{array}$} \\
\hline & Fowl & Man & Mouse & Guinea-pig \\
\hline M. anatis & 0 & 2 & 2 & 2 \\
\hline M. gallisepticum (s6) & 4 & 8 & 8 & 32 \\
\hline M. gallisepticum (A 514) & nt $\dagger$ & $\mathrm{nt}$ & $\mathrm{nt}$ & 32 \\
\hline IOWA 695 & 0 & 4 & nt & 2 \\
\hline WR I & 64 or $>$ & 64 or $>$ & 16 & 64 or $>$ \\
\hline M. bovigenitalium (PG I I) & 0 & 0 & 0 & 2 \\
\hline DONETTA & 0 & 2 & 0 & 0 \\
\hline M. agalactiae & 0 & 2 & 8 & 4 \\
\hline M. pneumoniae (FH) & 0 & 2 & 0 & 0 \\
\hline M. neurolyticum (PG 22) & 0 & 0 & 2 & 0 \\
\hline PG 5 & 0 & 0 & 0 & 2 \\
\hline B I & 2 & I6 & 16 & 16 \\
\hline B 2 & 0 & 0 & 0 & 4 \\
\hline B 3 & 0 & 0 & 2 & 0 \\
\hline B 5 & 0 & 4 & 2 & 4 \\
\hline
\end{tabular}

\footnotetext{
* Highest dilution of antigen which caused agglutination of approximately $75 \%$ or more of the erythrocytes.

$\dagger \mathrm{nt}=$ not tested.
}

\section{Haemagglutination inhibition}

Because of the low h.a. titres, exhaustive inhibition tests with specific rabbit antisera were not made. However, those mycoplasmas for which it was possible to use 4 h.a. units were tested and, in addition, mycoplasma PG 5 . The results, together with those of metabolic inhibition tests performed on the same antisera, are shown in Table 6. With the exception of mycoplasma WR I, the titres obtained by h.i. were much lower 
than those obtained by m.i. Heterologous h.i. titres were not determined in each case, but antiserum to mycoplasma WR I did not inhibit haemagglutination by Mycoplasma gallisepticum and vice versa.

Table 6. Haemagglutination inhibition with hyperimmune rabbit sera

\begin{tabular}{lcr}
\multicolumn{1}{c}{$\begin{array}{c}\text { Homologous antiserum titre (reciprocal) } \\
\text { measured by }\end{array}$} \\
Mycoplasma & $\begin{array}{c}\text { Haemagglutination } \\
\text { inhibition }\end{array}$ & $\begin{array}{c}\text { Metabolic } \\
\text { inhibition }\end{array}$ \\
M. gallisepticum (A 5I4) & 80 & 640 \\
WR I & I60 & 20 \\
PG 5 & 320 & $\mathrm{nt}$ \\
B I & 80 & I280
\end{tabular}

\section{DISCUSSION}

Several factors were shown to be important for the demonstration of haemadsorption. However, the most interesting discovery was that haemadsorption with some mycoplasma strains was inhibited when there were large numbers of colonies crowded on agar medium. The occurrence of this phenomenon may explain the failure of others to detect haemadsorption for mycoplasmas other than Mycoplasma pneumoniae. Our observation is similar to that of Somerson, Purcell, Taylor-Robinson \& Chanock (1965), who found that $\beta$-haemolysis of guinea-pig erythrocytes in an agar overlay was completely inhibited by crowding of colonies of $M$. pneumoniae. There is an apparent anomaly in the occurrence of inhibition of haemadsorption by crowding of colonies on agar medium and the lack of inhibition of haemadsorption to confluent sheets of the same mycoplasma adherent to glass under liquid medium as shown by Taylor-Robinson \& Manchee (I967a). This may be due to the fact that nutrients and waste products are freely diffusible in a liquid medium but not in a solid medium, and the exhaustion of a particular nutrient or the accumulation of a waste product may be responsible for the inhibition of haemadsorption when there are a large number of colonies on agar.

Although colonies of all strains of Mycoplasma gallisepticum and all strains of $M$. pneumoniae haemadsorbed, this was not true for other mycoplasmas tested. The fact that one strain within a serotype haemadsorbed did not mean that other strains within the same serotype would do so, and such differences were not due to variation in the number of colonies on agar. Notable examples of this were seen with strains of $M$. bovigenitalium and M.pulmonis. Thus, the PG 34 strain of the latter haemadsorbed, but the 'Negroni' strain of the same serotype did not. It is interesting that some strains of $M$. pulmonis haemadsorb, since Berg \& Frothingham (196I) reported that tissue culture cells infected with this organism haemadsorbed. Whether colonies of a non-haemadsorbing mycoplasma strain could acquire by continuous passage the ability to haemadsorb or, conversely, whether those of a haemadsorbing mycoplasma could lose this ability is unknown. In this respect, colonies of recently isolated strains of $M$. pneumoniae haemadsorb and so do those of the FH strain after over 300 passages in liquid and on solid medium; whether the FH strain haemadsorbed originally is unknown.

The titres obtained in haemadsorption-inhibition tests were much lower than in 
comparable metabolic-inhibition tests. Because of the low haemadsorption-inhibition titres, cross-tests to determine specificity were not performed. In addition, because of its insensitivity we have not been able to use the technique as a routine one for measuring antibody. Haemadsorption by itself, however, has a useful place in a mycoplasma diagnostic scheme. After isolating a mycoplasma we determine, among other characteristics, its ability to haemadsorb. Since only a few mycoplasmas haemadsorb, this limits the range of specific antisera required to identify a haemadsorbing mycoplasma; as a first choice, we select antisera prepared against those mycoplasmas known to haemadsorb and use them in disc growth-inhibition (Clyde, 1964) or metabolic inhibition (Taylor-Robinson et al. 1966; Purcell et al. 1966 b). Furthermore, we have found the phenomenon of value in examining a mixed mycoplasma population. About I0 \% of the colonies produced by a culture of Mycoplasma hyorhinis haemadsorbed. These haemadsorbing colonies, which apart from this characteristic were indistinguishable from the others, were cloned and identified as $M$. agalactiae. This eliminated the possibility that the haemadsorbing colonies were mutants of $M$. hyorhinis. In fact, of the many mycoplasma strains examined, we have not observed both haemadsorbing and non-haemadsorbing colonies belonging to strains of a particular serotype although, as noted previously, different strains may show one or other characteristic. This may be due to the picking of single colonies for the production of stock cultures.

Table 7. Correlation between haemadsorption and haemagglutination

\begin{tabular}{lcc}
\multicolumn{1}{c}{ Mycoplasma } & $\overbrace{\text { Haemadsorption }}^{\text {Presence (+) or absence (-) of }}$ & Haemagglutination* \\
$M$. gallisepticum (A 5I4) & + & $+(32)$ \\
$M$. agalactiae & + & $+(2)$ \\
$M$. pneumoniae & + & $+(8)$ \\
B I & + & $+(16)$ \\
$M$. pulmonis (PG 22) & + & - \\
$M$. pulmonis (PG 34) & + & $+(64$ or $>)$ \\
WR I & - & $+(2)$ \\
$M$. neurolyticum & - & - \\
$M$. fermentans & - & -
\end{tabular}

* Haemagglutination titres are shown in parentheses.

Mycoplasmas from various sources were found also to haemagglutinate although usually at a low titre. Those that did so best were those isolated from birds, such as Mycoplasma gallisepticum and mycoplasma WR I. $M$. pneumoniae haemagglutinated at a much lower titre than that reported by Feldman \& Suhs (1966). Their test is performed in the presence of horse serum which contains agglutinins for the particular erythrocytes used in the test. It appears that the haemagglutination is due to an additive effect of these agglutinins and $M$. pneumoniae agglutinin, each of which alone is present in a subagglutinating concentration (John, Stahl \& Fulginiti, I966). It is possible that if this principle were applied to mycoplasmas that we have found to haemagglutinate to low titre, higher titres might be attained. In several tests the haemagglutination that we have observed could be inhibited with specific antiserum, and the inhibition was specific where tests to determine this were performed.

Of considerable interest is the lack of correlation between haemadsorption and 
haemagglutination. This is shown in Table 7. Some mycoplasmas haemadsorb and haemagglutinate; others haemadsorb but do not haemagglutinate. In such instances, inability to haemagglutinate might be due to too low a concentration of antigen, although this seems unlikely, since the antigens of Mycoplasma pulmonis strains were derived from cultures containing $10^{8}$ viable organisms $/ \mathrm{ml}$. More striking are those mycoplasmas which do not haemadsorb under any circumstances and yet agglutinate in the case of mycoplasma WR I a variety of erythrocytes to high titre. It was suspected initially that haemadsorption might be a more sensitive expression of haemagglutination. Clearly this is not so in all cases, and underlines the fact that the mechanisms involved are not understood. The occurrence of tiny projections on the surface of M. gallisepticum particles has been observed in electron micrographs by Chu \& Home (1967).The appearance is similar to that of myxoviruses, and the projections are possibly haemagglutinin in nature. It is also possible that an erythrocyte receptor mechanism similar to that known to exist for myxoviruses may play a part in mycoplasma haemagglutination and haemadsorption.Thus, it has been indicated that in the haemagglutination reaction, a sialic acid at the surface of turkey erythrocytes provides binding sites or receptors for $M$. gallisepticum (Gesner \& Thomas, 1965), although in other experiments (Roberts, 1967) the removal of receptors on chicken erythrocytes for this mycoplasma was not achieved. In view of these contradictions, further investigations are warranted.

Finally, it is worth considering the possible relationship of haemadsorption and haemagglutination to mycoplasma pathogenicity. Mycoplasma pneumoniae infections are often associated with the production of a cold-agglutinin response. Somerson, Walls \& Chanock (1965) have postulated that the organism alters the erythrocyte membrane in some way, rendering it antigenic, and that adsorption of the organism to the erythrocyte is the first stage in this process. Furthermore, mycoplasmas adhere to cells other than erythrocytes. Thus, adherence to neutrophils, eosinophils, monocytes, lymphocytes, tissue culture cells and spermatozoa has been demonstrated (Zucker-Franklin, Davidson \& Thomas, I966a, b; Taylor-Robinson \& Manchee, $1967 b$ ). In addition, not only $M$.pneumoniae but also $M$. gallisepticum, M. pulmonis and $M$. agalactiae are pathogenic for their particular bird or animal host. All these mycoplasmas haemadsorb and it is possible that this or their ability to adhere to other tissue cells is the first stage in pathogenesis. Clearly, however, haemadsorption cannot be considered a factor in the pathogenesis of all mycoplasma infections. Thus, both strains of $M$. mycoides did not haemadsorb and this mycoplasma is highly pathogenic, being a major cause of cattle disease in several parts of the world. Gourlay $\&$ Shifrine (I966) have suggested that the pathogenicity of this organism is due to the production of a hypersensitivity reaction in the animal host.

We thank those persons from whom we obtained mycoplasmas and Mrs Susan Beveridge for technical assistance.

Note added in proof. Subsequent serological studies have shown that mycoplasma strains B I, B 2 and B 5 are similar to Mycoplasma gallinarum, strain B 4 is similar to $M$. laidlawii and strain в 6 is similar to $M$. iners. 


\section{REFERENCES}

Berg, R. B. \& Frothingham, T. E. (I96I). Haemadsorption in monkey kidney cell cultures of Mycoplasma (PPLO) recovered from rats. Proc. Soc. exp. Biol. Med. ro8, 6I6.

Butler, M. \& Leach, R. H. (1964). A mycoplasma which induces acidity and cytopathic effect in tissue culture. J. gen. Microbiol. 34, 285.

Chanock, R. M., Hayflick, L. \& Barile, M. F. (I962). Growth on artificial medium of an agent associated with atypical pneumonia and its identification as a PPLO. Proc. natn. Acad. Sci., U.S.A. $48,4 \mathrm{I}$.

CHU, H. P. \& HoRne, R. W. (1967). Electron microscopy of $M$. gallisepticum and $M$. mycoides using the negative staining technique and their comparison with myxovirus. Ann. N.Y. Acad. Sci. 143, 190.

Clarke, D. H. \& Casals, J. (1958). Techniques for haemagglutination and haemagglutination inhibition with arthropod-borne viruses. Am. J. trop. Med. Hyg. 7, 56I.

Clyde, W. A., JUN. (I964). Mycoplasma species identification based upon growth inhibition by specific antisera. J. Immun. 92, 958.

Del Grudice, R. A. \& PAvia, R. (I964). Hemadsorption by Mycoplasma pneumoniae and its inhibition with sera from patients with atypical pneumonia. Bact. Proc. p. 7I.

Dierks, R. E., Newman, J. A. \& Pomeroy, B. S. (1967). Characterization of avian mycoplasma. Ann. N.Y. Acad. Sci. 143, I70.

Edward, D. G. ff. \& FreundT, E. A. (I965). A note on the taxonomic status of strains like 'Campo' hitherto classified as Mycoplasma hominis type 2. J. gen. Microbiol. 4I, 263.

Fallon, R. J., Grist, N. R., Inman, D. R., Lemcke, R. M., Negroni, G. \& Woods, D. A. (I965). Further studies of agents isolated from tissue cultures incoculated with human leukaemic bone marrow. Br. med. J. ii, 388.

Feldman, H. A. \& Suhs, R. H. (1966). Serologic epidemiologic studies with M. pneumoniae. I. Demonstration of an haemagglutinin and its inhibition by antibody. Am. J. Epidemiol. 83, 345 .

Gesner, B. \& Thomas, L. (1965). Sialic acid binding sites: role in hemagglutination by Mycoplasma gallisepticum. Science, N.Y. I5r, 590.

Gourlay, R. N. \& Shifrine, M. (I966). Antigenic cross-reactions between the galactan from $M y c o-$ plasma mycoides and polysaccharides from other sources. J. comp. Path. Ther. 76, 4I 7 .

Hayflick, L. (1965). Tissue cultures and mycoplasmas. Tex. Rep. Biol. Med. (Suppl. I), 23, 288.

John, T. J., Stahl, M. \& Fulginiti, V. A. (1966). Cumulative hemagglutination by Mycoplasma pneumoniae and other agglutinins. J. Bact. 92, 1002.

Jungherr, E. L., Luginbuht, R. E. \& JACOBS, R. E. (I953). Pathology and serology of air sac infection. Proc. Am. vet. Med. Ass. 9oth ann. meet, 303.

LEACH, R. H. \& BUTLER, M. (I966). Comparison of mycoplasmas associated with human tumours, leukemia, and tissue cultures. J. Bact. 91, 934.

Purcell, R. H., Taylor-Robinson, D., Wong, D. C. \& Chanock, R. M. (1966b). A color test for the measurement of antibody to the non-acid-forming mycoplasma species. Am. J. Epidemiol. 84,51 .

Purcell, R. H., Somerson, N. L., Fox, H., Wong, D. C., Turner, H. C., \& Chanock, R. M. (1966a). Identification of acid-inducing agent and related mycoplasmas as M. hyorhinis. J. natn. Cancer Inst. 37, $25 \mathrm{I}$.

Roberts, D. H. (1964). Serotypes of avian mycoplasma. J. comp. Path. Ther. 74, 447.

Roberts, D. H. (1967). Neuraminidase-like enzyme present in Mycoplasma gallisepticum. Nature, Lond. $21_{3}, 87$.

Somerson, N. L., Walls, B. E. \& Chanock, R. M. (1965). Hemolysin of Mycoplasma pneumoniae tentative identification as a peroxide. Science, $N . Y$. 150, 226.

Somerson, N. L., Purcell, R. H., Taylor-Robinson, D. \& Chanock, R. M. (1965). Hemolysin of Mycoplasma pneumoniae. J. Bact. 89, 813.

TAYloR-Robinson, D. \& MANCheE, R. J. (I967 a). Adherence of mycoplasmas to glass and plastic. J. Bact. 94, I78I.

TAYLOR-RobInson, D. \& MANCheE, R. J. (1967b). Spermadsorption and spermagglutination by mycoplasmas. Nature Lond. 215, 484. 
Taylor-Robinson, D., Purcell, R. H., Wong, D. C., \& Chanock, R. M. (1966). A colour test for the measurement of antibody to certain mycoplasma species based upon the inhibition of acid production. J. Hyg., Camb. 64, 91 .

VAN HERCK, W. \& EATON, M. D. (I945). An unidentified pleuro-pneumonia-like organism isolated during passages in chick embryos. J. Bact. 5o, 47.

Zucker-Franklin, D., Davidson, M. \& Thomas, L. (1966a). The interaction of mycoplasmas with mammalian cells. I. Hela cells, neutrophils, and eosinophils. J. exp. Med. 124, 521 .

Zucker-Franklin, D., Davidson, M. \& Thomas, L. ( $1966 b)$. The interaction of mycoplasmas with mammalian cells. II. Monocytes and lymphocytes. J. exp. Med. 124, 533.

\section{EXPLANATION OF PLATE}

Fig. I. Representative colonies from an agar plate which contained 8000 colonies of Mycoplasma agalactiae; incubated at $37^{\circ}$ for $15 \mathrm{~min}$. with guinea-pig erythrocytes. No adsorption observed after excess erythrocytes removed. $\times 250$.

Fig. 2. A representative colony from an agar plate which contained 80 colonies of Mycoplasma agalactiae; incubated with guinea-pig erythrocytes. Adsorption after excess erythrocytes removed. $\times 250$. 

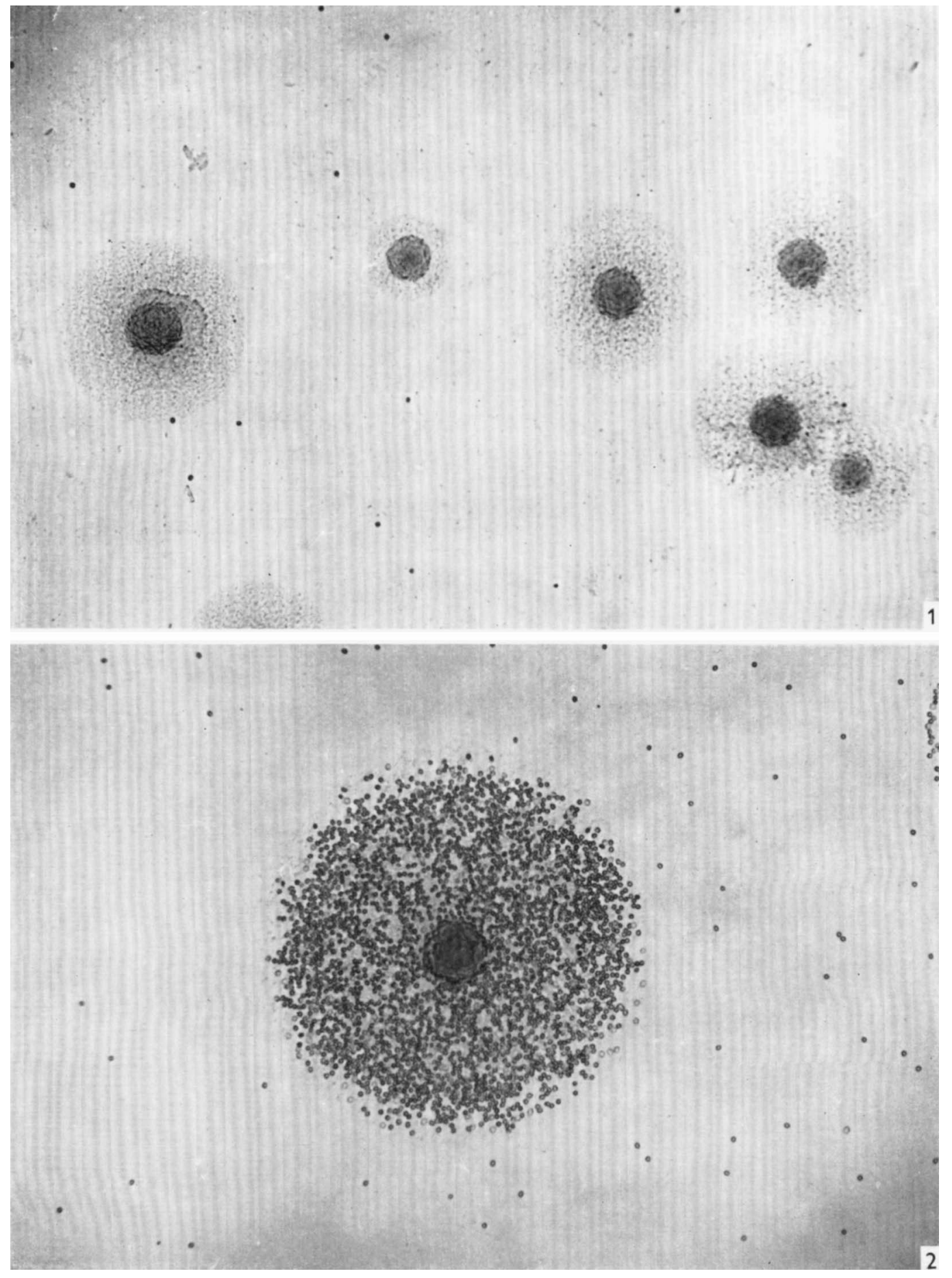